\title{
Un continente en el sistema internacional. Notas sobre la soberanía estatal desde América Latina. De Doctrinas a Teorías
}

\section{A continent in the international system. Notes on state sovereignty through Latin America. From Doctrines to Theories}

\author{
Silvia T. Álvarez \\ Universidad Nacional del Sur \\ Departamento de Humanidades \\ Bahía Blanca, Argentina \\ (iD https://orcid.org/0000-0001-5587-5910 \\ alvarezt@bblanca.com.ar
}

\begin{abstract}
Resumen
El objetivo central de esta investigación es identificar los aportes del pensamiento latinoamericano al concepto de soberanía, a través de Doctrinas y Teorías, en un recorrido que también se concibe como parte de la conformación de la disciplina de las Relaciones Internacionales. Dicho abordaje se realizará a partir de la comprensión de los conceptos en su historicidad, razón por la cual el contexto de producción de las ideas analizadas será el marco de referencia así como la consideración de las dimensiones de la soberanía a las que se apunta, como poder (igualdad jurídica, integridad territorial, exclusión de actores externos en toma de decisiones internas) y control (flujo de personas, bienes y servicios a través de las fronteras). Se trata de determinar los modos en que a través de las Doctrinas y las Teorías se construyeron significados y sentidos diversos de su realización, se plantearon límites y posibilidades a través de la historia contemporánea, desde la
\end{abstract}

Cómo citar este artículo/ How to cite this artículo. Álvarez, S. T. (2021). Un continente en el sistema internacional. Notas sobre la soberanía estatal desde América Latina. De Doctrinas a Teorías. Revista de Historia Americana y Argentina, 56 (2), pp. 233-273. https://doi.org/10.48162/rev.44.018 
conformación de los estados soberanos en el siglo XIX hasta su crisis en los umbrales del siglo XXI. Por medio de este análisis, se apunta a problematizar el Pacto westfaliano que dio origen al supuesto de un sistema internacional regido por estados soberanos.

Palabras clave: soberanía; doctrinas; teorías; América Latina.

\begin{abstract}
The central objective of this research is aimed at identifying the contributions of Latin American thought to the concept of sovereignty, through Doctrines and Theories, in a journey that is also conceived as part of the conformation of the discipline of International Relations. This approach will be executed from the understanding of the concepts in their historicity, thus the context of production of the analyzed ideas will be the frame of reference as well as the consideration of the dimensions of sovereignty to which it is aimed, such as power (legal equality, territorial integrity, exclusion of external actors in internal decision-making) and control (flow of people, goods and services across borders). The porpose is to identify the different meanings and senses of its realization, limits and possibilities through Doctrines and Theories in contemporary history, from the formation of sovereign states, in the 19th century, to its crisis on the threshold of the 21st century. From this analysis, the aim is to problematize the Westphalian Pact that originated an international system governed by sovereign states.
\end{abstract}

Key Words: sovereignty; doctrines; Theories; Latin America.

Recibido: 13/04/2021 Aceptado: 24/06/2021

\title{
Introducción
}

Las bases generales de la soberanía estatal en el sistema político moderno, reconocen sus orígenes formales en el Tratado de Westfalia (1648) a través del cual se instaura un orden internacional signado por los principios de igualdad jurídica, integridad territorial y exclusión de actores externos en los asuntos internos de los estados. Si bien para algunos autores no representa un cambio del status internacional y, por tanto, la significación que se le otorga es incorrecta, mítica y, consecuentemente, falsa (Beaulac, 2000; Osiander, 2001; Teschke, 2003; Akashi, 2010; Shibasaki, 2014), sentó un nuevo derecho entre los estados, marcó el inicio del moderno Derecho Internacional público y estableció las bases del sistema interestatal contemporáneo. Así, se convirtió en el marco referencial de las relaciones 
internacionales y estipuló lo permitido y lo no permitido en relación a las disputas de los espacios político-económicos (Aceves López, 2016, pp. 7273). En otros términos, inauguró una época en la cual buscarían establecerse las reglas de las relaciones interestatales (Blin y Marin, 2013, p. 216) que encontrarían en la soberanía su principal referencia ${ }^{1}$.

El principio de la soberanía alude a la naturaleza, los alcances y los límites de la influencia de unos actores sobre otros. La soberanía es el derecho, la cualidad o el poder que tiene el soberano, siendo este la máxima autoridad sobre todo lo demás que no reconoce otro poder sobre él. Es cualidad del poder del estado, en el sentido de que no existen, dentro de esa territorialidad ni fuera, de ella mandatos superiores. Significa, al interior del estado, la expresión de la "voluntad" popular para el estado de derecho, en general, y las democracias contemporáneas, en particular. Es también, como soberanía externa, atributo del estado en cuanto unidad suprema de decisión respecto de la población de un territorio, reconociendo cuatro dimensiones: legal, westfaliana e interdependiente (Krasner, 2001). La soberanía legal internacional se vincula con los conceptos de igualdad jurídica e independencia de los estados. Alude a los derechos y deberes internacionales, que incluyen los derechos a la defensa, la conservación, la jurisdicción, la independencia; la existencia de normas efectivas que protejan los derechos de todos y cada uno de los miembros de la comunidad internacional; y la igualdad en la adopción de nuevas normas, lo cual significa que ningún estado puede estar obligado a aceptar una norma cuando no ha concurrido expresa o tácitamente a su aceptación. La soberanía westfaliana es definida como el atributo del estado basado en su territorialidad y la exclusión de protagonistas externos en las estructuras de autoridad de un territorio dado. La soberanía interdependiente, por último, se refiere a la capacidad de las autoridades públicas para regular el flujo de información, ideas, bienes, gentes, sustancias contaminantes o capitales a través de las fronteras del Estado en cuestión. Comprende los derechos que asisten a los actores (estados, regiones, pueblos) a ejercer autoridad y control sobre "un bien que se considera propio" en un espacio determinado.

${ }^{1}$ En la obra citada se hace referencia a reglas de gobernanza mundial. No obstante, difiere del sentido "global" empleado desde los años 90 del siglo XX. Ver Concept of governance, en UNESCO (s.f). International Bureau of Education. http://www.ibe.unesco.org/en/geqaf/technical-notes/concept-governance 
La soberanía, secularmente, ha carecido centralidad en los estudios sociales como una categoría de análisis en el pensamiento político occidental: la idea de que el orden westfaliano en el que todos los estados son, si no igualmente poderosos, sí igualmente soberanos (Bonilla, 2014, pp. 330-331). No obstante, principalmente en los últimos veinte años, han aumentado los análisis sobre las tensiones entre sus principios y su realización (Krasner, 2001; Rutherford, 2012); la problematización en torno a la dimensión histórica y antropológica de la soberanía (Wachspress, 2009); el interrogante sobre la existencia de un estado sin soberanía (Geertz, 2004); la soberanía como construcción de la modernidad (Hardt y Negri, 2002); la relación colonial entre Occidente y Oriente como base constitutiva del desarrollo y práctica de la soberanía (Pormoukhtari, 2013); o la relativización de los cambios que la globalización produce sobre el poder de los estados (Arrighi, 1998). Finalmente, los análisis vinculados a la concepción de una soberanía limitada, relativa o dependiente (Meyer, 2008; Ojeda (1986 [1927]) expresan las tensiones entre un poder supremo y la imposibilidad, o amenazas, a su existencia. Como señala Imanuel Wallerstein (2017), "Tal vez no haya ninguna otra palabra en el vocabulario público común de dirigentes políticos y analistas académicos que tenga tantos significados y usos en conflicto como soberanía. La única otra que se acerca en confusión es liberalismo" y, por lo tanto, "el término mismo no nos dice nada".

En América Latina, la soberanía ha generado diversas lecturas debido a los límites/obstáculos/desafíos que amenazan su efectiva existencia; a las bases teóricas de su propio origen, que remiten a la realidad europea, lo cual plantea interrogantes no sólo sobre su identidad sino sobre su capacidad explicativa para determinar la existencia de un sistema westfaliano en otros tiempos y espacios; pero también, en razón de que la soberanía es una construcción epistémica ajena, en principio, a las propias cosmovisiones "latinoamericanas". Estas lecturas, además, se contextualizan en una historia que -enmarcada en las luchas de poder de los hegemones- recorre los orígenes culturales de la región, la independencia y la constitución de estados soberanos en el siglo XIX, su consolidación como tales en el siglo $X X$ y su revisión en el marco de la creciente globalización que se profundiza desde finales del siglo $\mathrm{XX}$ y pondría a prueba -en un sentido global- la soberanía como cualidad del poder estatal en diálogo/tensión con reivindicaciones identitarias y locales. 
Como correlato, a través de la historia, se han configurado distintos postulados, ideas y conceptos, dirigidos a interpretar la realidad latinoamericana y trazar mapas analíticos y propositivos capaces de responder a las límites/obstáculos/desafíos/amenazas que provienen de las políticas de poder de las grandes potencias, que tienen como base el supuesto de la "igualdad jurídica" de los estados en el sistema internacional. Los mismos se han conformado a través del tiempo al compás de los instrumentos analíticos dominantes en los abordajes del sistema internacional, hasta la primera mitad del siglo XX, desde el Derecho Internacional y, a partir de entonces, por medio de la propia configuración de la disciplina de las Relaciones Internacionales.

En América Latina, el Derecho Internacional estuvo vinculado a la construcción doctrinaria. Las Doctrinas se presentan como fuente de tal derecho (Menezes, 2010; Cançado Trindade y Martínez Moreno, 2003) y, en cierto modo, se constituyen en antecedentes de las teorías de las Relaciones Internacionales, ya que mientras las Doctrinas son construcciones eidéticas que, fundamentalmente, tienen protagonismo en los tiempos en que domina el estudio de las Relaciones Internacionales desde la perspectiva de la Diplomacia y el Derecho Internacional, las Teorías, ya avanzados en el siglo XX, lo son de la disciplina de las Relaciones Internacionales (Arenal, 1981, p. 856 y ss.).

Las Doctrinas, desde un punto de vista jurídico, constituyen modelos o principios de política exterior e internacional, generalmente elaborados por juristas, gobernantes, diplomáticos o referentes políticos dirigidos a explicar y desentrañar la correcta implementación del derecho o dar respuestas para temas controvertidos que no encuentran bases jurídicas para su resolución y que incumben a desafíos propios de los estados, de la sociedad civil y/o de los organismos internacionales. Desde un punto de vista político, se presentan también como mapas de ruta para sus formuladores porque dan cuenta de un particular problema que requiere de una respuesta específica, del lugar desde donde se formula y su relación con la región, el sistema internacional y el mundo en general; orienta sobre concepciones en torno a la política, la vida democrática, el derecho o las modalidades de inserción internacional; y configura, a través de la articulación entre ellas, itinerarios en la construcción de una identidad regional y de la propia autonomía (Devés y Álvarez, 2020, p. 15). Las Doctrinas, así, representan también orientaciones o estrategias de política exterior (Ver Tovar Ruiz, 2011). 
Las Teorías se presentan como un conjunto de generalizaciones que incluyen un gran número de hechos, relacionados e integrados entre sí, cuyos resultados es posible anticipar con algún grado de confianza. De esta manera, abren el camino a nuevas observaciones y generalizaciones que amplían el campo del conocimiento (Tomassini, 1988, p. 2). Por su parte, una Teoría en las relaciones internacionales define su campo de estudios, y propone un mapa cognitivo dirigido a describir y explicar la estructura y el funcionamiento del sistema internacional contemporáneo y sus tendencias dominantes, para ofrecer, con base en estas, proyecciones relativamente confiables (Tomassini, 1988, p. 5). En América Latina, las Teorías han buscado aportar caminos alternativos a los propuestos tradicionalmente por Occidente -constituidos en mainstream- para elaborar mapas teóricos dirigidos a dar respuesta a la propia realidad en función de proyectos propios en términos políticos, económico-sociales y/o culturales.

Bajo estos supuestos, es necesario reconocer, a los fines del análisis de la historia latinoamericana y sus posibles proyecciones en el tiempo, otras formas de conocimiento que han contribuido a conformar la comprensión de lo que es América Latina y de su inserción en el mundo (Heredia, 2008, p. 8). En este sentido, el estudio de los conceptos representa un modo de interpretar la realidad de un país o una región determinados en un marco temporal específico (Cervo, 2013). En el campo de las Relaciones Internacionales, si bien existe un creciente interés por el rol de los mismos, las investigaciones desarrolladas en el Sur desde lecturas históricas aún son incipientes (Chagas-Bastos, 2018). Los conceptos, entre ellos, la soberanía, se presentan como partes referenciales de las distintas construcciones eidéticas, desde las Doctrinas a las Teorías, y su abordaje contribuye a problematizar los aportes del pensamiento latinoamericano a ese campo a través de la historia.

El objetivo central de esta investigación está dirigido a identificar, a modo de notas, los aportes del pensamiento latinoamericano al concepto de soberanía, a través de Doctrinas y Teorías, en un recorrido que también se concibe como parte de la conformación de la disciplina de las Relaciones Internacionales. Dicho abordaje se realizará a partir de la consideración de los conceptos en su historicidad, razón por la cual el contexto de producción de las ideas analizadas será el marco de referencia así como la identificación de las dimensiones de la soberanía en tanto poder (integridad territorial, igualdad jurídica, exclusión de actores externos en toma de decisiones internas) y control (flujo de personas, bienes y servicios a través 
de las fronteras). En este abordaje, se reconocerá la valoración jurídica, política, económica y/o cultural de la soberanía. Se trata de determinar los modos en que, desde las Doctrinas y las Teorías, se construyeron significados y sentidos diversos desde su realización, sus límites y sus posibilidades a través de la historia contemporánea, para llegar a su consideración como mito, dominación o liberación, en una trayectoria que parte de la conformación de los estados modernos en el siglo XIX, hasta su crisis en los umbrales del siglo XXI. A través de este análisis, se apunta a problematizar el Pacto westfaliano que dio origen al supuesto de un sistema internacional regido por estados soberanos.

\section{Las Doctrinas² y la soberanía}

Los primeros años del siglo XIX significaron para España, Portugal e Inglaterra, la pérdida de las colonias americanas, en gran medida alentada por la Revolución francesa de 1789. Sin embargo, en 1815, las monarquías absolutas retornaban al poder, a través de la Santa Alianza, buscarían el mantenimiento del statu quo asociado a la lucha contra el conato y la propagación de movimientos revolucionarios, y llegarían a plantear la intervención en América con el objetivo de restablecer la autoridad del rey de España en los nuevos estados independizados.

Por su parte, desde América, el presidente de Estados Unidos, James Monroe, en su discurso anual ante el Congreso, el 2 de diciembre de 1823, anunciaba una Doctrina que constituiría en un principio rector de la política exterior de Estados Unidos, dirigida a impedir cualquier intervención de las potencias europeas en los asuntos internos de los estados americanos, al sostener que "El principio con el que están ligados los derechos e intereses de los Estados Unidos es que el continente americano, debido a las condiciones de la libertad y la independencia que conquistó y mantiene, no puede ya ser considerado como terreno de una futura colonización por parte de ninguna de las potencias europeas" (Monroe, 1823).

${ }^{2} \mathrm{El}$ análisis que sigue reconoce como aportes centrales los recogidos en Devés y Álvarez (2020): Witker (Doctrina Drago); Clemente (Doctrina Larreta); Coloma (Doctrina Tobar); Figueroa Jiménez (Doctrina Díaz Ordaz); Sánchez Mugica (Doctrinas Juárez, Carranza, Estrada); Álvarez (Doctrina Brum, Doctrina de la Tercera Posición); Álvarez y Devés (Doctrinas Calvo y Saavedra Lamas). 
Si bien el hecho desencadenante derivó de la pretensión rusa de llevar su soberanía en el continente americano hasta los $50^{\circ}$ de latitud Norte, fue concebida por sus autores, en especial John Adams, como una crítica de los Estados Unidos al colonialismo frente a la amenaza que suponía la restauración monárquica en Europa y la Santa Alianza tras las guerras napoleónicas (Fernández Palacios, 2011, p. 73). En otros términos, un estado americano, recientemente independiente de un estado europeo, vindicaba su cualidad de poder soberano y, por tanto, el propio Pacto westfaliano.

Para América, la Doctrina Monroe sentó las bases para mostrar su lugar en el propio concierto continental y en relación con Europa. La soberanía sería una clave interpretativa que, con el correr del tiempo, serviría de argumento para sostener lecturas panamericanistas 0 latinoamericanistas, fundamentalmente, estas últimas a partir de fines del siglo XIX, cuando Estados Unidos comenzaba a formar parte de las nuevas potencias que, por entonces con Japón, se iniciaban en políticas de poder de carácter imperialista. Las Doctrinas estarían dirigidas, ya a consolidar al estado soberano, ya a situarlo en un contexto internacional regido por el derecho a través de construcciones institucionales de carácter multilateral 0 a problematizar en torno al poder político del y en el estado.

\section{La soberanía como realización: en cumplimiento del Pacto}

El estado, como sujeto del sistema internacional, tiene la obligación de asumir las consecuencias jurídicas de un acto cuando viola una norma que lo obliga dentro de ese sistema. Como señala Francisco Bello (1970, pp. 78), este principio surgió en la segunda mitad del siglo XIX, como una vía de solución legal para los conflictos derivados de reclamos pecuniarios de un estado a otro, de súbditos de distintos estados. En América Latina, la aplicación del principio de responsabilidad internacional llegó a plantear el restablecimiento de la dominación europea en América, porque sobre el respeto a las normas (tratados o convenciones) la respuesta fue la amenaza del uso de la fuerza o la invasión armada.

En el contexto referido, la conformación y el desarrollo de los estados que resultaron de los procesos independentistas requerían de un Derecho Internacional capaz de dar respuestas a problemas que surgían en el plano de nuevas relaciones de carácter interestatal (Menezes, 2010, pp. 23-24). Y en este sentido, un nuevo imperialismo constituiría para los estados 
americanos la primera prueba de que la soberanía del nuevo continente requería de su autoafirmación y salvaguarda, fundamentalmente, en términos de igualdad jurídica, territorialidad y no intervención. Las Doctrinas Juárez, Calvo y Drago se inscriben en estas dimensiones de la soberanía, en tiempos en que el cobro de deudas contraídas por los estados con otros estados o sus connacionales justificaba la intervención en los países deudores. Así ocurrió en México, entre 1864 y 1867, período durante el cual gobernó el país el Segundo Imperio bajo el mando de Maximiliano, y en 1902, cuando las potencias europeas (Alemania, Inglaterra e Italia) realizaron un Bloqueo Naval a Venezuela, en razón de las deudas impagas de Venezuela a ciudadanos de dichos países.

La Doctrina Juárez (1867) ${ }^{3}$ vindica el sentido basal de la soberanía estatal, asociado a la integridad territorial, la inviolabilidad de las fronteras y la exclusión de actores externos en la toma de decisiones internas, al tiempo que plantea la importancia de la soberanía interna como conjunción de fuerzas sociales y políticas, las que, a través de las leyes y las autoridades, son corresponsables de los derechos de todos sus habitantes. Sin embargo, "la base última de la soberanía es de carácter popular, lo cual implica libertad de elegir y obediencia a las autoridades emanadas de tal soberanía" (Juárez, 1998, p. 465). Su afirmación "Que el pueblo y el gobierno respeten el derecho de todos. Entre los individuos, como entre las naciones, el respeto al derecho ajeno es la paz" (Juárez, 1998, p. 465), en rigor, sintetizan la Doctrina.

Con bases argumentativas semejantes a la Doctrina Juárez, en relación a la ausencia del derecho de las grandes potencias a vulnerar los derechos de los estados débiles, la Doctrina Calvo (1868) ${ }^{4}$ aborda el principio de soberanía estatal asociado a la exclusión de actores externos en la toma de decisiones internas al sostener que los extranjeros residentes en un estado, que sufran algún perjuicio en el país de acogida, deben recurrir a los tribunales de dicho país, y no solicitar la intervención de su estado de origen, sea a través de la vía diplomática o la fuerza (Suñé, 2015). Implica la igualdad ante la ley de nacionales y extranjeros; la sujeción de los

${ }^{3}$ La Doctrina se expone en el mensaje que el presidente de México, Benito Juárez (1858-1872), pronunciara el 8 de diciembre de 1867 ante el Congreso, con motivo de reanudarse la vida constitucional en el país.

${ }^{4} \mathrm{La}$ Doctrina Calvo fue formulada por el jurista argentino Carlos Calvo, en su obra Derecho Internacional teórico y práctico de Europa y América (1868). 
extranjeros a las leyes y jueces nacionales; y la abstención de los estados extranjeros de intervenir en las controversias patrimoniales de sus nacionales en terceros países.

Finalmente, la Doctrina Drago $(1902)^{5}$, en sentido semejante, pero ya en relación a los estados, y expuesta como una extensión de la Doctrina Monroe con vistas a ser realizada en un plano continental ${ }^{6}$, parte del principio de igualdad jurídica entre los estados, y plantea que "Entre los principios fundamentales del derecho público internacional que la humanidad ha consagrado, es uno de los más preciosos el que determina que todos los Estados, cualquiera que sea la fuerza de que dispongan, son entidades de derecho, perfectamente iguales entre sí y recíprocamente acreedoras por ello las mismas consideraciones y respeto" (1903, pp. 2-3). Sobre la base de tal supuesto, y sin eludir el principio de responsabilidad internacional, condena el principio de intervención realizado a través del cobro compulsivo de deudas porque "El acreedor sabe que contrata con una entidad soberana y es condición inherente de toda soberanía que no pueda iniciarse ni cumplirse procedimientos ejecutivos contra ella, ya que ese modo de cobro comprometería su existencia" (p. 2). De esta manera, se condena el "cobro coercitivo de deudas contractuales", porque, además, ello significaría para las naciones más débiles la ruina y a la sumisión frente las más poderosas.

La Doctrina Drago no sería aceptada por Estados Unidos, país que optaría por elaborar el Corolario Roosevelt (1904), una continuación de la Doctrina Monroe ${ }^{7}$. Por este Corolario, América Latina se constituía en espacio de los intereses comerciales de Washington que protegería a través de la intervención en los asuntos de cualquier país que amenazara los derechos o propiedades de sus ciudadanos. De este modo, justificaba la hegemonía en América Latina y su intervencionismo en los asuntos de las repúblicas independientes (Castro Peña, 2007, p. 76). Este Corolario supuso, en realidad, una carta blanca para la intervención de Estados Unidos en

${ }^{5}$ La Doctrina fue elaborada por Luis María Drago, en carácter de ministro de Relaciones Exteriores del presidente argentino Julio A. Roca (1896-1904) a través de una nota enviada al ministro argentino en Washington, Martín García Mérou, el 29 de diciembre de 1902.

${ }^{6}$ Para la reconstrucción de historia de la Doctrina Drago, ver Conil Paz, 1975.

${ }^{7}$ Para un recorrido del curso seguido por la Doctrina Drago desde un lectura teórica en clave regional, ver Clemente, 2020. 
América Latina y establecía de facto derechos "quasi o neocoloniales" sobre países de la región. Así, el Corolario Roosevelt daría las bases argumentativas a la Política del Gran Garrote (Tah Ayala, 2021), bajo la cual se legitimó el empleo de la fuerza como medio para defender los intereses en el sentido más amplio- de los Estados Unidos, lo que resultaría en numerosas intervenciones políticas y militares en todo el continente. El apoyo a Panamá en su separación de Colombia (1903), la ocupación militar de la República Dominicana (1916-1924), y en Cuba (1906-1909) y la ocupación militar de Haití son ejemplos de tal política (Tah Ayala, 2021).

Avanzada la primera década del siglo XX, hacia el fin de la Primera Guerra Mundial, mientras Estados Unidos se consolidaba como primera potencia económica en el plano internacional, México sentaba las bases del constitucionalismo social a través de la sanción de la Constitución de 1917, presentándose como fundante en el plano global. Esta última, resultado de una revolución social que reconoció la propiedad originaria de los recursos, se implementaría en un escenario convulsionado a nivel socio-político. Las empresas, entre ellas las grandes petroleras y el gobierno estadounidense, comenzaron a ejercer presión sobre el gobierno de Carranza, a través de intimidaciones y campañas de desprestigio contra el gobierno y que llegarían a la amenaza de la intervención armada, porque sentían que la nueva Constitución (artículos 27, 30 y 130) afectaba sus intereses.

Como respuesta a la amenaza de intervención, la Doctrina Carranza ${ }^{8}$ (1918) sostiene que todos los estados son iguales, deben respetar sus instituciones, leyes y soberanía, no les asiste derecho de intervenir en los asuntos interiores de otro y, por tanto, todos deben someterse estrictamente y sin excepciones al principio universal de no intervención; nacionales y extranjeros deben ser iguales ante la soberanía del país en que se encuentran. Por último, y como consecuencia de lo anterior, las legislaciones deben ser uniformes e iguales en lo posible, sin establecer distinciones por causa de nacionalidad, excepto en lo referente al ejercicio de la soberanía (Citado de Gaytán, 2018).

${ }^{8}$ La Doctrina fue presentada por el presidente de México, Venustiano Carranza, el 1 de septiembre de 1918 ante el Congreso. 
Si razones económicas para la intervención por parte de las potencias originaron la Doctrina Carranza, fueron razones políticas las que inspiraron la redacción de la Doctrina Estrada (1930) ${ }^{9}$. Por un lado, hacia fines de la década del '20 y durante la siguiente, América Latina asistió a golpes de estado que interrumpieron el curso de sus regímenes democráticos y dieron pie a la intervención de las grandes potencias, como Estados Unidos; por otro, México, país de origen de la Doctrina, debió defender, frente a las grandes potencias, su derecho al reconocimiento como estado (Ver Aguirre Cortés, 2014), en parte por sus interrupciones en el orden constitucional pero también por los cambios que significó la Revolución Mexicana y la Constitución de 1917, que perjudicaba las intereses de países como Estados Unidos. El reconocimiento de gobiernos sería considerado como medio de presión política para obtener concesiones, ventajas y privilegios de los países que sufrían crisis políticas. En tal sentido, esta Doctrina adoptaba una posición contraria a la Doctrina Tobar $(1907)^{10}$, un llamado a los estados americanos a intervenir de modo indirecto en las discusiones internas de otros estados ante gobiernos de facto que surgieran de revoluciones contra la constitución y que habría ejercido influencia en el presidente estadounidense Woodrow Wilson cuando éste no reconoció al gobierno del mexicano José Huerta en 1913 (Elizalde, citado de Coloma, en Devés y Álvarez, 2020, p. 235).

La Doctrina Estrada parte de los principios de igualdad jurídica y no intervención de los estados a los fines de respetar el principio de la autodeterminación de los pueblos, que implica, en este caso, el rechazo la práctica del reconocimiento de gobiernos por motivos políticos. Como señala Moya Domínguez (2004), en el plano axiológico, esta Doctrina optó por privilegiar el principio de la no-intervención en los asuntos internos de los Estados, en vistas de la realidad sociológico-política continental, pues creía innecesario y negativo para las relaciones internacionales investigar sobre la legalidad del gobierno de un Estado. Sobre la base de la "Teoría del reconocimiento" de los gobiernos, entiende que el reconocimiento es una práctica denigrante, hiere la soberanía de las naciones y coloca a sus regímenes políticos bajo la evaluación de otros estados. En consecuencia,

${ }^{9} \mathrm{Su}$ autor, Genaro Estrada Félix, Secretario de Relaciones Exteriores de México durante la Presidencia de Pascual Ortiz Rubio (1930-1932), quiso denominarla Doctrina mexicana. Fue redactada y publicada mediante un comunicado, el 27 de septiembre de 1930.

10Ver Coloma, Doctrina Tobar (Devés y Álvarez, 2020). 
el gobierno de México se limitaría a mantener o retirar, cuando lo creyera procedente, a sus agentes diplomáticos y a continuar aceptando, cuando también lo considerase procedente, a los similares agentes diplomáticos que las naciones respectivas tuvieran acreditados en el país, sin calificar, ni precipitadamente ni a posteriori, el derecho de las naciones extranjeras para aceptar, mantener o sustituir a sus gobiernos o autoridades (citado en Calderón Salazar, 1996). De este modo, cambiaba la práctica de 'reconocimiento' por la de 'continuación de las relaciones diplomáticas' y respetaba la igualdad jurídica como el derecho a la insurrección (Valverde, 1961), una lectura que sería retomada años más tarde en la Doctrina Díaz Ordaz $^{11}$.

Las Doctrinas Juárez, Drago, Calvo, Carranza y Estrada se presentaron como declaraciones dirigidas a salvaguardar la soberanía de los estados en términos del cumplimiento de postulados asociados a la igualdad jurídica de los estados, la integridad territorial, la exclusión de actores externos en la toma de decisiones internas y la condena al "derecho" de intervención. Todas ellas coincidieron en declaraciones relativas a la protección del estado, como entidad soberana y, en tal sentido, se presentaban como precisiones acerca de cómo se concebía la soberanía estatal y las reglas que otros estados debían respetar. Se trataba del cumplimiento del Pacto westfaliano.

\footnotetext{
${ }^{11}$ La Doctrina Díaz Ordaz está constituida por un conjunto de principios de política exterior promovidos por el entonces presidente de México, Gustavo Díaz Ordaz, desde 1966 a 1970 y cuyo contenidos se expresan en el discurso de toma de posesión de la presidencia, el 1 de diciembre de 1964 y el discurso del Secretario de Relaciones Exteriores Antonio Carrillo Flores, el 15 de abril de 1969. Considerada un matiz de la Doctrina Estrada, encuentra entre sus principios la defensa del pluralismo ideológico en las relaciones internacionales; el respeto a las decisiones de otros pueblos; el reconocimiento diplomático entre estados, independientemente del carácter u orientación de los gobiernos (Carrillo Flores, 1965-1966). La cuestión del reconocimiento de gobiernos se resuelve desde la neutralidad e imparcialidad o, si se quiere, en una discrecional voluntad por parte de los estados de continuar relaciones diplomáticas, más allá del cariz de gobiernos, y siempre en virtud de la adecuación de aquellas relaciones con los intereses nacionales fundamentales (Carrillo Flores, 19651966; Torres, 2010; Ortiz Ahlf, 2018).
} 
La soberanía como supuesto del sistema interestatal

La Primera Guerra Mundial (1914-1918) tuvo, hacia la última etapa de su desarrollo, en Estados Unidos uno de sus principales protagonistas. Había ingresado en la misma junto a los Aliados en 1917 y un año más tarde, su presidente, Woodrow Wilson, daría a conocer al mundo catorce puntos dirigidos a sentar las bases de un Nuevo Orden Mundial que, tras el fin de las hostilidades, habría de regirse por los principios del Derecho Internacional. Entre ellos, se encontraba la fundación de una Liga de las Naciones que cobraría realidad en el Tratado de Versalles (1919), aunque Estados Unidos, finalmente, nunca ingresaría en ella. Ante la Guerra, América Latina estuvo dividida entre los estados que optaron por la neutralidad o el alineamiento. Uruguay, que se inscribió en este último grupo, expresaría la necesidad de propiciar una política panamericana en vistas de los cambios a los que asistía el sistema internacional, a través de la Doctrina Brum, una "aquiescencia" con las políticas de Washington (Russell y Tokatlian, 2013, p. 165 y ss.) desde donde se planteaba, fundamentalmente, una interpretación continentalista del pasado y el futuro de la región sobre la base de la soberanía estatal.

La Doctrina Brum (1920)12 constituye una propuesta de multilaterización de la Doctrina Monroe (Atkins, 2019) a través de la creación de una alianza defensiva representada en una Liga Americana de Naciones que protegería la soberanía de los estados americanos, principalmente en su territorialidad, sobre la base de una solidaridad continental que reconociera la igualdad jurídica de tales estados. A partir de estas ideas, Baltasar Brum sintetizaba su propuesta en postulados que buscaban conciliar el principio de soberanía estatal con el de solidaridad continental y se resumen del siguiente modo: 1) Juzgamiento de actos internos a un estado según sus propias leyes, salvo reclamaciones diplomáticas que podrán ser admitidas en casos de denegación evidente de justicia. 2) Reconocimiento de la nacionalidad de nacimiento a hijos de extranjeros nacidos en el continente americano, salvo si, obtenida la mayoría de edad, se encontrara en el estado de origen y manifestara su deseo de optar por la nacionalidad de éste. 3) Actuación uniforme y común de todos los estados americanos frente a agravios extracontinentales a cualquiera de ellos. 4) Constitución de una Liga

${ }^{12}$ Fue elaborada por Baltasar Brum, presidente del Uruguay (1919-1923) y expuesta por primera vez en una conferencia que brindara el 21 de abril de 1920, en la Universidad de Montevideo. 
Americana, sobre la base de la igualdad de sus integrantes. 5) Sometimiento al juicio arbitral de la Liga de controversias entre estados americanos, en caso de que no pudieran resolverse por las partes. 6) Consideración por parte de la Liga Americana de controversias entre un estado americano, - solo a su solicitud- y la Sociedad de las Naciones (Brum, 1920).

Por su parte, el contexto en el que Saavedra Lamas presentó su Doctrina, la década del '30, estuvo dado por la política de Estados Unidos dirigida a revertir su imagen de potencia imperialista bajo del "Gran Garrote" e iniciar una Política de buena vecindad ${ }^{13}$, y el revisionismo -desde Europa y Asiade los estados insatisfechos por las cláusulas del Tratado de Versalles (1919) que encontraba su expresión en el nacionalismo, el militarismo y el expansionismo territorial. Ese contexto representó también un nuevo avance de Estados Unidos sobre América Latina y una prueba de fuerza entre la amenaza de una nueva guerra mundial y los principios del Derecho Internacional. Desde la Argentina, la Doctrina Saavedra Lamas representaría, al mismo tiempo, una estrategia dirigida a tomar distancia del panamericanismo y una prédica por el derecho, donde la soberanía estatal también se presentaría como una base central de sus postulados.

En el marco de las negociaciones de paz ante el conflicto por la disputa del Chaco Boreal entre Bolivia y Paraguay (1932-1935) (Berasategui, 2009), una Comisión de Neutrales, integrada por Estados Unidos, Colombia, Cuba, México y Uruguay, en 1932 proponía sanciones contra el Estado que continuara las hostilidades, cuando el otro deseara detenerlas (Escudé y Cisneros, 2000). La Argentina rechazó la propuesta por considerar que solo representaba un instrumento legal que podía justificar una injerencia de carácter coercitivo y ponía en peligro los principios básicos del Derecho Internacional. Así nacía el Pacto Antibélico de No Agresión y Conciliación (1933), conocido como Pacto Saavedra Lamas, e interpretado como la Doctrina Saavedra Lamas ${ }^{14}$. Fue suscrito por Argentina, Brasil, Chile,

\footnotetext{
${ }^{13}$ Una iniciativa presentada por la administración del presidente Franklin Delano Roosevelt en el marco de la VII Conferencia Panamericana de Montevideo en diciembre de 1933.

${ }^{14}$ Saavedra Lamas sostendría las ideas centrales de este Pacto a través de su vida. La Doctrina alcanzaría su formulación durante las gestiones del argentino Carlos Saavedra Lamas como Ministro de Relaciones Exteriores en el gobierno de Agustín
} 
México y Uruguay; y más tarde se adhirieron Colombia, Bolivia, El Salvador, Costa Rica y países europeos como Bulgaria, España, Grecia y Portugal. El posicionamiento de la Argentina pondría en evidencia su renuencia a seguir los dictados de Washington, en una línea de carácter panamericanista, para proponer otra de carácter iberoamericano o proeuropeo (Zuccarino, 2019; 2018 , p. 3), a través de la cual expresaba sus preferencias por los seculares lazos económicos con Gran Bretaña, país al que Estados Unidos desplazaba del escenario latinoamericano desde la Primera Guerra Mundial; pero también planteaba un posicionamiento ante el Derecho Internacional.

El Pacto tuvo como una de sus cláusulas centrales la condena a las guerras de agresión, el no reconocimiento de las adquisiciones territoriales por la fuerza y el arreglo de conflictos por medios pacíficos. La Doctrina, de carácter pacifista y neutralista, constituye una declaración vinculada al principio de respeto a la soberanía, en términos de territorialidad, y dirigida a esfuerzos colectivos de carácter internacional.

Los fundamentos se inspiraban en el deseo de contribuir a la paz, que se traducían en beneficios materiales y humanos para el mundo, pero también en la adhesión a los esfuerzos realizados por los estados en pro de la armonía universal y la solución de conflictos o divergencias por medios pacíficos. A los fines de la aplicación del Pacto, se consideró necesario crear una organización permanente de conciliación de los conflictos internacionales. En caso de incumplimiento, por cualquier estado en conflicto, de las obligaciones estipuladas en el mismo, los estados contratantes se comprometían a emplear todos sus esfuerzos para el mantenimiento de la paz. Para ello, adoptarían en su calidad de neutrales una posición común y solidaria; pondrían en funcionamiento los medios políticos, jurídicos o económicos autorizados por el Derecho Internacional; y harían gravitar la influencia de la opinión pública (Pacto Antibélico de no agresión y conciliación, 1933).

Tanto la Doctrina Brum como la Doctrina Saavedra Lamas, representaron con intencionalidades políticas distintas en el escenario continental- un análisis jurídico de la soberanía, en términos de integridad territorial, igualdad jurídica y no intervención, pero con una proyección relacional de tipo interestatal. En este sentido, resultan herederas de la Doctrina Drago,

Pedro Justo (1932-1938), en el marco de las negociaciones de paz ante el conflicto por la disputa del Chaco Boreal entre Bolivia y Paraguay (1932-1935).

RHAA v.56 n.2, 2021. ISSN: 0556-5960, ISSNe 2314-1549. CC BY-NC-SA 4.0 
cuya realización requeriría cooperación internacional de carácter multilateral.

\section{La soberanía como poder del "pueblo"}

Tras la Segunda Guerra Mundial, se asistió al fin de los imperialismos en Asia y África y, consecuentemente, surgieron nuevos estados soberanos en el marco del principio de la autodeterminación de los pueblos, uno de los principios basales y fundacionales de la Organización de las Naciones Unidas (1945) y de la Declaración Universal de los Derechos Humanos. La Guerra Fría, por su parte, planteaba una división ideológica mundial entre Estados Unidos, por un lado, asociado a la democracia y el capitalismo, y la Unión Soviética, por otro, identificada con el comunismo. En América Latina, esa división se expresaría a través del alineamiento con Estados Unidos vía política panamericanistas, como la planteada por la Doctrina Larreta desde Uruguay, y otras de carácter autonomista, como la predicada por la Doctrina de la Tercera Posición en la Argentina, ambas asociadas con las posibilidades o límites del alineamiento hemisférico con Estados Unidos (Trask, 2015). Estas Doctrinas abordarían, con sentidos diferentes, la soberanía desde un punto de vista político.

La Doctrina Rodríguez Larreta $(1945)^{15}$, inspirada por el gobierno de Estados Unidos, proponía considerar y discutir la posibilidad de una "acción colectiva multilateral" ante regímenes de fuerza que violaran los derechos del hombre y del ciudadano, por más que no constituyeran una amenaza para la paz (Cerrano, 2019; Clemente, 2012). De este modo, la soberanía estatal estaba subordinada a la existencia de un gobierno democrático regido por los derechos humanos. En tal sentido, afirmaba que el principio de no intervención no podía ser amparo para la violación de los derechos del hombre y de los acuerdos hemisféricos aprobados en las conferencias interamericanas. Los límites de la soberanía eran por primera vez planteados en una Doctrina latinoamericana en un plano multilateral. La misma habría tenido por objetivo reunir a los estados americanos en una acción común contra el régimen militar imperante en Argentina y el ascenso

\footnotetext{
${ }^{15}$ Elaborada desde Uruguay, por Eduardo Rodríguez Larreta, como ministro de Relaciones Exteriores del gobierno de Juan José de Amézaga (1943-1947) a través de una nota dirigida a las cancillerías americanas titulada "Paralelismo entre la democracia y la paz: protección internacional de los derechos del hombre. Acción colectiva en defensa de esos principios".
} 
de uno de sus integrantes, el coronel Juan Domingo Perón, quien se postulaba para la presidencia y ganaría las elecciones el 26 de febrero de 1946. Perón, llegado a la presidencia, terminaría de dar forma a la Doctrina de la Tercera Posición (1947) ${ }^{16}$, cuyos principios comenzaron a plantearse durante su gestión en el régimen militar que daba a su fin. La Doctrina se presentaría, entonces, como la búsqueda del equilibrio necesario entre la aceptación del liderazgo de Estados Unidos en el mundo occidental, con quien convenía aliarse estratégicamente en la búsqueda de la reinserción internacional (Rapoport y Spiegel, 2009) y aquella parte de la sociedad que consideraba a Perón como símbolo de la defensa del interés nacional y la soberanía frente a las políticas de poder de aquel mismo país (Barelli, 2008).

Si la Doctrina Larreta relativizó la soberanía estatal por estar está sujeta al respeto y ejercicio de los derechos humanos en el ámbito interno a un estado, la Doctrina de la Tercera Posición inauguraba, en términos doctrinarios, el principio de la soberanía como libertad de acción de un estado y poder sobre su territorio y población a partir de la independencia económica y la justicia social. Lograda la justicia social y la independencia económica, era posible la soberanía política y se daban, así, las condiciones necesarias para emprender una política exterior propia e independiente (1948, p. 4). Si los estados, en el manejo de sus políticas exteriores, se encontraban comprometidos con la causa de la paz universal, según esta Doctrina, debían respetar el principio según el cual todos los estados eran soberanos y, por tanto, no reconocían una autoridad superior y podrían darse las bases de un gobierno cooperativo mundial, basado en la solidaridad, el cumplimiento de los acuerdos internacionales y el compromiso efectivo en la resolución pacífica de los conflictos (1947, p. 235). La soberanía estatal, más cercana a la autonomía decisional, no vendría dada por los límites impuestos a otros estados o a las acciones

\footnotetext{
${ }^{16}$ Consiste en una propuesta de política exterior sintetizada en la defensa de los principios de independencia económica, justicia social y soberanía política que reconoce su origen formal el 7 de julio de 1947, en un mensaje dirigido por el Presidente de la Argentina, Juan Domingo Perón (1946-1955), a todos los pueblos del mundo a través de más de mil emisoras radiales, donde buscaría formular un conjunto de principios superadores del capitalismo y el comunismo, a los que consideraba símbolos del materialismo contemporáneo, el imperialismo y la opresión de individuos y pueblos.
} 
multilaterales. En el fondo, se trataría de un ejercicio al interior del estado y sustentado también en la soberanía popular.

La Doctrina Larreta y la Doctrina de la Tercera Posición aportarían una significación política a la soberanía, desde una lectura panamericanista y otra autonomista, en tanto ponderación del poder del estado, los actores que la ejercen y los valores que la limitan o posibilitan. En este sentido, los ciudadanos y la soberanía popular vendrían a incorporarse como sujetos del poder hacia el interior del estado, en directa relación con la soberanía estatal a la que pondría límites.

\section{Las Teorías y la soberanía}

Tras la Segunda Guerra Mundial, en el marco de un mundo bipolar signado por la Guerra Fría, la defensa de la soberanía representaría para América Latina un medio de realizar su autonomía frente a las políticas de poder de Estados Unidos y la Unión Soviética que se disputaban el dominio del mundo. El período fue testigo de la descolonización de África y Asia y, consecuentemente, el surgimiento de nuevos estados soberanos, mientras se conformaba un Tercer Mundo que buscaría márgenes de autonomía frente a las grandes potencias. En este nuevo escenario, a la tradicional agenda política militar, se agregaba otra que, desde la periferia, encontraba en la economía la clave interpretativa del sistema internacional y de su lugar en él.

Hacia fines del siglo $X X$, en el escenario de la Posguerra fría y la globalización aparecieron nuevos centros de poder como resultado de un proceso que tiende a la multipolaridad. La agenda internacional incorporó a las tradicionales problemáticas político-militares, las cuales perdieron relevancia, temas vinculados al crecimiento de la economía de mercado, el progreso tecnológico, el bienestar social, la protección del medio ambiente, la autonomía nacional y la identidad cultural. Se trata de cuestiones que incluyen una transformación espacial de las relaciones y las transacciones sociales, generando flujos y redes transcontinentales o interregionales que afectan, en última instancia, al ejercicio del poder. La consideración de la sociedad civil como actor destacado y la importancia asignada a sus vinculaciones con actores estatales y extraestatales, propicia la existencia de otros escenarios decisionales, donde las relaciones internacionales en particular se resignifican (Álvarez, 2016). 
Desde las grandes potencias, bajo el liderazgo de Estados Unidos, en el que la Organización de Naciones Unidas tiene un rol protagónico, el objetivo del "nuevo orden mundial" consiste en mantener un sistema regido por la paz y la seguridad, pues ello permite liberar los recursos humanos y materiales necesarios para los fines propuestos, siendo la extensión de la democracia y el mercado -cuya ideología es el neoliberalismo- centrales en una agenda que se presenta como global. En este contexto, se genera un creciente compromiso de los estados en redes regionales y globales, que conduce a un cuestionamiento del alcance de la autoridad estatal y, por tanto, la soberanía. América Latina busca integrarse al "nuevo orden" y en ella dominan políticas de alineamiento con las grandes potencias, especialmente Estados Unidos.

Hacia los albores del siglo XXI, se inicia un cuestionamiento del "orden" dominante y comienza a configurarse una etapa vinculada al rol protagónico del estado y, con éste, un retorno de la política. Se cuestiona la concepción del estado mínimo y el alineamiento automático con las grandes potencias, particularmente Estados Unidos, en la búsqueda por redefinir el rol del estado y las vías de su inserción internacional. Asimismo, la emergencia de movimientos sociales enmarca nuevas realidades que expresan fenómenos de exclusión y desigualdad sociocultural y, de esta manera, la política, se torna cultural y se expresa en el plano societal. La soberanía, en crisis en el marco de la hegemonía de la globalización neoliberal, reingresa consecuentemente a un campo esencialmente político (Álvarez, 2016).

Si la soberanía estatal adquiere nueva relevancia, los estados, a un mismo tiempo, buscan reivindicarla e integrarla en el plano de la soberanía regional, en donde actores gubernamentales y civiles deben dirigirse a mancomunar propuestas y políticas que presenten a América Latina como un bloque soberano frente a los actores externos. Este cambio se refleja, por ejemplo, en la conformación de la Alternativa Bolivariana (ALBA) primero y, más tarde, en la Unión Sudamericana de Naciones (UNASUR) y la Comunidad de Estados de América Latina y el Caribe (CELAC) ${ }^{17}$.

${ }^{17}$ EI MERCOSUR, inscripto inicialmente en el regionalismo abierto y asociado a una relativización, en un sentido formal, de la soberanía, también inicia un camino semejante. Ver Álvarez, 2012. 
De esta manera, se asiste a un nuevo protagonismo de la soberanía, en su doble dimensión, externa e interna, pero, al mismo tiempo, en una noción superior de la misma, de corte regional. Ahora se fundamenta en la soberanía popular, en el poder constituyente, para sentar las bases de una nueva institucionalidad. La importancia de la soberanía interna, asociada a los pueblos, llega a adquirir una dimensión transnacional -claramente expuesta en el ALBA, en particular- a través de la diplomacia de los pueblos (Díaz Martínez, 2013). Se expresa como un reflejo de la propia relevancia de los movimientos sociales dentro de los bloques regionales (de naturaleza básicamente estatal) y contribuye a poner en evidencia la dimensión de la soberanía interna, intrínsecamente propia al Estado, proyectándose a una soberanía regional.

En el plano teórico, desde mediados del siglo $\mathrm{XX}$ y en el marco de los recorridos señalados, se desnaturaliza el rol jurídico de la soberanía, su cualidad de poder como un elemento dado del estado, permanente e inmutable (Estructuralismo latinoamericano), se lo desmitifica (Realismo Periférico) o des/cubre (Estudios decoloniales). Desde cada una de esas lecturas, se concibe a la soberanía como posibilidad, como mito o como dominación y liberación.

\section{La soberanía como posibilidad}

Hacia fines de los años '40 del siglo XX, Raúl Prebisch desde la Comisión Económica para América Latina y el Caribe (CEPAL) sentó las bases del Estructuralismo Latinoamericano ${ }^{18}$ en un escenario signado por la descolonización, el avance del estado de bienestar y la hegemonía de las Teorías clásicas del desarrollo, que consideraban el desarrollo y el subdesarrollo como parte de un proceso común y continuo. Para Prebisch, la estructura de las relaciones económicas entre el Centro y la Periferia tienden a reproducir las condiciones de subdesarrollo y a aumentar la distancia entre los países desarrollados y los países periféricos, a través de la apropiación de los frutos del progreso técnico y de las diferencias en el

\footnotetext{
${ }^{18}$ Sus aportes son diversos y pueden reconocerse, a modo de ejemplo, en los años '60, a través de Fernando Henrique Cardoso y Enzo Faletto, desde la Teoría del Desarrollo; la Teoría de la Dependencia, representada por Ruy Mauro Marini y Theotonio dos Santos y, ya en los '80, en el marco de la globalización neoliberal, el Neoestructuralismo, desarrollado por Osvaldo Sunkel y Raúl Bernal Meza, o las Teorías críticas de la globalización expuestas por Aldo Ferrer y Mario Rapoport.
} 
aumento constante de la productividad que beneficiaba a las economías industrializadas. Esta estructura, desarrollo-subdesarrollo, es mantenida y perpetuada a través de la división internacional del trabajo.

Más allá de sus diferencias a través del tiempo y los enfoques que se presentan en su seno (desde las Teorías del Desarrollo a las Teorías de la Dependencia, o desde el Estructuralismo al Neoestructuralismo), comparten las siguientes ideas: los estados nacionales como segmentos imperialistas 0 colonizados, dominantes o dependientes, de una misma estructura internacional; la relevancia de los actores internos y externos al estado en la explicación en el desarrollo de las relaciones internacionales y su participación en las mismas como parte de un proceso global de desenvolvimiento del capitalismo mundial; la lectura de las relaciones internacionales desde una visión histórica; la preponderancia otorgada a los factores económicos en la formación y transformación de la estructura jerárquica de las relaciones internacionales; y la problematización ${ }^{19}$ en torno a las posibilidades reales de alterar esa jerarquía (Tomassini, 1988, pp. 5861).

El Estructuralismo latinoamericano, en rigor, no toma como eje articulador central la noción de soberanía, sino trata fundamentalmente las relaciones de dependencia de la periferia con respecto al centro, pero aporta ideas que determinan que el déficit de desarrollo latinoamericano se debe a una influencia exógena histórica que ha afectado la autonomía de sus estados y su propia soberanía, y pone incluso en crisis al estado nación (Jaguaribe, 1979, pp. 91-96). En tales casos, el concepto del poder que prima en el pensamiento realista es incorporado como autonomía, entendida como la capacidad de defender la soberanía nacional (Tickner, 2012). Osvaldo Sunkel sintetiza, en parte, lo que llama la necesidad de promover un nacionalismo del desarrollo, como un esfuerzo de afirmación nacional, una aspiración a la autodeterminación y a la soberanía (1967, p. 16).

La soberanía, en los análisis estructuralistas, cobra mayor relevancia en el marco del discurso globalizador de los años ' 90 asociado a la crítica al fin del protagonismo del estado y de un mundo de fronteras abiertas. Hacia principios del siglo XXI daría lugar a una etapa en donde dominó un regionalismo de carácter poshegemónico, crítico de Estados Unidos, más

${ }^{19}$ Tomassini, en realidad, habla de pesimismo. 
aún, caracterizado por la exclusión explícita de este (Serbín, 2010, p. 5) y por la restitución del rol del estado.

En 1984, Aldo Ferrer, Raúl Prebisch y Celso Furtado publicaron el libro Deuda y soberanía, donde plantean la centralidad del poder del estado. Más tarde, en un trabajo publicado en 1989, cuando la hegemonía de la globalización neoliberal comenzaba a proyectar en la región, Ferrer sostiene que en un mundo crecientemente globalizado, el desarrollo debía pasar por la adopción de una estrategia de crecimiento "hacia afuera", lo cual era reforzado por la incapacidad del estado como agente soberano en el manejo de la economía en un mundo interdependiente. En un análisis sobre la globalización, Ferrer afirma que la soberanía no es un status jurídico sino el ejercicio real del poder sobre su propio territorio:

En el transcurso de los últimos doscientos años, las asimetrías crecientes en el desarrollo económico de los países resultan del ejercicio del poder por las potencias dominantes pero, en última instancia, dependen de la aptitud de cada sociedad para participar en las transformaciones desencadenadas por el avance de la ciencia y sus aplicaciones tecnológicas. En este último sentido, puede decirse que cada país tiene la globalización que se merece. Es claro que el ejercicio efectivo de la soberanía es un requisito para que un país pueda dar respuestas propias al escenario global (Ferrer, 2007, pp. 433-434).

Según este autor, las ideas fundantes de la política económica de los países exitosos nunca estuvieron subordinadas al liderazgo intelectual de países más adelantados y poderosos que ellos mismos. De ahí que el estado haya sido el instrumento esencial para poner en práctica las ideas del desarrollo nacional y la vinculación soberana con el contexto externo (p. 436). En otras palabras, con la soberanía se viabiliza la autonomía y se posibilita el desarrollo (Ferrer, 2012).

En esta línea, en el escenario de la globalización neoliberal, observa Helio Jaguaribe (2001) que los países considerados en nivel de dependencia se confrontan con la alternativa de, o bien completar su desarrollo e incrementar significativamente su capacidad económico-tecnológica, elevándose al nivel de resistencia, o "desnacionalizarse" y perder el margen del que todavía disponen de autonomía interna y externa, en cuyo caso, aunque conservando la "parafernalia formal de la soberanía", se convertirían en meros segmentos del mercado internacional, dirigidos exógenamente por 
multinacionales y grandes potencias y, por tanto, administradores de estas fuerzas. Desde esta lectura, para Jaguaribe, persiste, en tales países, la "soberanía formal": himno, bandera, ejércitos y elecciones, pero las decisiones relevantes son dictadas por fuera de sus fronteras.

Asimismo, parte de la obra de Theotonio dos Santos, que reúne trabajos escritos entre 1962 y 2012 por Mónica Bruckman y Francisco López Segrera, y editada bajo el sugerente título Construir soberanía. Una interpretación económica de y para América Latina, expresa una de las ideas que cobran relevancia en su pensamiento principalmente desde fines del siglo XX, frente al discurso de la globalización. Nuevamente, la soberanía es entendida como ejercicio del poder hacia las fronteras interiores de los estados, donde adquiere centralidad la soberanía nacional. En palabras de Dos Santos, "Lo que falta al Tercer Mundo es soberanía nacional para defender y preservar sus recursos, y producir con libertad los bienes necesarios para sus pueblos" (2020, p. 585) ${ }^{20}$. En sentido semejante, "La integración latinoamericana depende no sólo de una unidad de acción política y diplomática entre los Estados de la región sino, sobre todo, de la capacidad de generar instancias autónomas de decisiones, instituciones, estructuras sociales y políticas aptas para garantizar la soberanía de cada país" (2020, p. 785) ${ }^{21}$.

También Mauro Ruy Marini aborda la centralidad de la soberanía en relación a la democracia y la dependencia:

En América Latina, hablar de democracia implica, como supuesto necesario, plantear el tema de su capacidad para autodeterminarse, es decir, de fijarse sus metas en libertad, atendiendo primariamente a las exigencias de sus pueblos. Es, pues, evocar el tema de la dependencia en que se encuentra la región en el plano del capitalismo internacional, y conduce, por ello mismo, a entender la lucha por la democracia en tanto que lucha de liberación nacional (Marini, 1985).

${ }^{20}$ Extraído de Dos Santos (2010). Economía regional y desarrollo sustentable: las nuevas tendencias y la integración latinoamericana.

${ }^{21}$ Extraído de Dos Santos, T. (2008). Del terror a la esperanza. Auge y decadencia del neoliberalismo. 
Por lo tanto, para el Estructuralismo, la soberanía, como posibilidad, es una potencia. Su realización depende del rol protagónico del poder político en el estado, y de los propios procesos de integración regional, y del poder de la sociedad, en clave de soberanía nacional. Antes, sin embargo, depende de la liberación de la secular estructura funcional del Centro, dominante, y la periferia, subordinada. De esta forma, la soberanía adquiere un rol político en tanto poder en ejercicio, es el poder real del estado, para llevar adelante sus políticas hacia los fines deseados y el ejercicio de la autonomía se presenta, en parte, como condición de la soberanía, y en parte, como su resultado.

\section{La soberanía como mito}

Desde una lectura que reconoce, y acepta, la existencia de un sistema internacional signado por la globalización, el triunfo del liberalismo y la hegemonía de Estados Unidos en los años '90, Carlos Escudé formula su Teoría, el Realismo Periférico, cuyos principios pueden resumirse del siguiente modo: la política exterior de un país vulnerable, empobrecido y poco estratégico debe ser del más bajo perfil posible, para evitar la confrontación, salvo en aquellos asuntos materiales vinculados en forma directa con su bienestar y su base de poder, adaptando sus objetivos políticos a los de esa potencia dominante; esta política exterior debe formularse teniendo en cuenta la relación costos-beneficios materiales y considerando los riesgos de costos eventuales; y, finalmente, ella requiere una reformulación y reconceptualización de la autonomía, en términos de la capacidad y los costos relativos de la confrontación (Bernal Meza, 2018, p. 78).

La teorización de Escudé encuentra en la soberanía una de las claves explicativas, desde donde desmitifica la existencia de este concepto. En este sentido, sostiene que el sistema internacional a través de la historia ha estado dominado por la existencia de una jerarquía interestatal, nunca reconocida formalmente por los estados poderosos y tampoco por las principales Teorías de las relaciones internacionales. La soberanía es calificada como un mito porque todos los estados, aún los más poderosos, están sometidos a límites en la "libertad de maniobra internacional". Tales límites ponen en evidencia el condicionamiento al que casi siempre está sujeto el ejercicio de la soberanía y que describe como una ley de hierro de la ciencia política. (Escudé, 2012, pp.15-18). En otros términos, en la expresión "Nadie tiene el derecho de mandar, nadie tiene la obligación de 
obedecer" se encuentra sintetizado el mito de la soberanía disfrazado [política] y de ciencia (2012, p. 90). No obstante sí existen soberanos, hegemones, a nivel internacional, necesarios para mantener el orden y la seguridad internacionales, particularmente desde fines del siglo XX, ante las amenazas de las armas de destrucción masiva y su empleo por los "enemigos de Occidente" o las propias amenazas producto de la globalización (Escudé, 2011; 2019).

Por lo tanto, para Escudé, esta lectura de la realidad, a la que califica de ideológica, se encuentra plagada de imágenes antropomorfas e incluso metafísicas del estado-"nación" y de sus cualidades, como la soberanía, siendo, entonces, un instrumento de legitimación del sistema interestatal y dirigido a un "emocionalismo funcional" para la movilización de lealtades "básico y legítimo del accionar nacionales", lo cual, a su vez, "ayudó a generalizar la idea de que la acumulación de poder y/o "seguridad" de parte del estado, frente a otros estados, es el objetivo político. Por consiguiente, en el pensamiento sobre las relaciones internacionales, el objetivo último ha sido siempre la acumulación de poder estatal" (2012, p. 71).

En otros términos, y basada su Teoría en la "hipocresía" de la igualdad que rige en el sistema internacional, postula que la soberanía se presenta como "una historia ficticia" o una "cosa a la que se atribuyen cualidades o excelencias que no tiene". Ese mito, construido por los "dioses" que representan en la historia las grandes potencias europeas y Estados Unidos, expresa, entonces, las tensiones entre los principios y la realidad, particularmente para los estados débiles, vulnerables y poco estratégicos de las grandes potencias. De este modo, se han traicionado los intereses de los ciudadanos, en beneficio de los intereses del estado y de sus élites dominantes (1995; p. 117; 1998; 2012, pp. 45-46).

Ser conscientes de ese mito sería el primer paso, en la lectura de Escudé, para una inserción internacional en interés y bienestar de los ciudadanos. En sus palabras, "El sacrificio del bienestar ciudadano se da por supuesto en forma inadvertida. No se comprende siquiera remotamente que lo que "tiene sentido" cuando se da por supuesto este sacrificio, deja de "tener sentido" si el bienestar ciudadano reina supremo como prioridad del Estado" (2012, p. 96). De ahí que los estados débiles, conscientes de sus vulnerabilidades y de su debilidad relativa, han de buscar el poder a través de la riqueza en vez de la competencia político-militar y ha de estar dirigido al bienestar de la ciudadanía (1995; 2012, p. 15). Así, la no confrontación, 
asociada a la actuación del lado del país con mayor poder político y económico, facilita el accionar externo del país periférico y le posibilita alcanzar niveles óptimos de crecimiento y desarrollo. De ahí también la concepción de autonomía, que ya no es definida como libertad de acción o maniobra, sino como "los costos de usar la libertad de elección o de maniobra que cualquier estado mediano tiene en forma casi ilimitada" (1995, p. 211).

De este modo, la soberanía, en su sentido formal y nominal, de naturaleza jurídica, es reemplazada por una "capacidad" de carácter políticoeconómico (por su posibilidad y fines). Sustentada en la democracia y dirigida a la ciudadanía, se traduce, en términos realistas, en la capacidad de maniobra de un estado a los fines deseados, el bienestar del ciudadano (Schenoni y Escudé, 2016, p. 12). La falacia antropomórfica del estado nación soberano cede su lugar a la relación estado-sociedad civil (extraída por Escudé de Robert Cox).

\section{La soberanía como dominación y liberación}

También en los años '90, a partir de los trabajos de Aníbal Quijano, desde una revisión crítica de las formas históricas de dominación política, económica, social y epistémica de Occidente, los estudios decoloniales ${ }^{22}$ buscan desnaturalizar la denominada realidad para pensar en un mundo en donde también otros mundos son posibles (Ramallo, 2014, p. 43). De acuerdo a tal enfoque, se sostiene que mientras el colonialismo designa una relación política y económica, en la cual la soberanía de un pueblo reside en el poder de otro pueblo o nación, la colonialidad se refiere a un patrón de poder que emergió como resultado del colonialismo moderno, pero que en lugar de estar limitado a una relación de poder político entre dos pueblos o naciones, alude a la forma como el trabajo, el conocimiento, la autoridad y las relaciones intersubjetivas se articulan entre sí a través del mercado capitalista mundial y de la diferencia colonial. Desde esta lectura, mientras el colonialismo precede temporalmente a la colonialidad, esta última sobrevive a aquél, de donde la colonialidad y la modernidad son parte de un mismo proceso que se inicia con la conquista y colonización de América en 1492 y que se perpetúa hasta el presente, dando como resultado una

\footnotetext{
${ }^{22}$ Figuran en esta corriente, entre otros intelectuales, Walter Mignolo, Arturo Escobar, Edgar Lander, Fernando Coronil, Santiago Gorosfoquel, Nelson Maldonado Torres y Enrique Dussel.
} 
imbricación de "jerarquías globales múltiples y heterogéneas («heterarquías») de formas de dominación y explotación sexuales, políticas, económicas, espirituales, lingüísticas y raciales, donde la jerarquía racial/étnica de la línea divisoria europeo/ no europeo reconfigura de manera transversal todas las demás estructuras globales de poder (Grosfoguel, 2006, p. 26; Gómez Vélez, Saldarriaga Grisales, López Gil. Zapata Botero, 2017, pp. 49-50).

Como resultado, se configura un sujeto que se adapta a una historia, un lenguaje y una existencia predeterminadas, la supeditación de un pueblo a otro, lo cual puede expresarse en que la soberanía de los países y poblaciones americanos ha residido en Europa occidental y más tarde también en Estados Unidos (Vélez et. al, 2017, p. 35). De esta manera, existe un "nexo históricamente estrecho entre el poder y la producción de conocimientos" (Galindo Rodríguez, 2013, p. 87) que invisibiliza lo no occidental. En esta línea, Santiago Castro-Gómez (2003) rastrea cómo, en el sistema filosófico, se ha impuesto la hybris del punto cero, perspectiva que encubre al punto de vista occidental como un punto de vista específico, y más bien, se asume como un punto de vista soberano que permite erigirse como universalismo abstracto, invisible y ubicuo. Así, la soberanía no constituye un fundamento prepolítico unívoco y estático para la vida política internacional/nacional, sino que ha formado parte de prácticas discursivas y retóricas que han sido redefinidas para dar sentido a tiempo y espacios políticos (Kunz, 2012).

Si modernidad y colonialidad forman parte de un mismo proceso y la propia modernidad cobra su significado por la colonialidad, la soberanía no encuentra sus orígenes en el Pacto westfaliano o al menos su completo sentido en aquel, sino solo si se la considera desde la conquista y colonización de América. Desde esta lectura, Walter Mignolo observa que la comunicación y la interacción entre cristianos y bárbaros fueron unilaterales ya que a estos últimos se les privó de soberanía, incluso cuando se les reconoció como iguales en virtud del derecho natural y del ius gentium. Así,

La Doctrina de la soberanía desarrolló su carácter a través del encuentro colonial. Esta es la historia oculta y más oscura de la soberanía, la cual no puede comprenderse mediante explicaciones de la Doctrina que presupongan la existencia de estados soberanos (Mignolo, 2015, p. 43). 
El corolario es un universalismo eurocéntrico excluyente que se perpetúa y realiza en el racionalismo de René Descartes y en el propio liberalismo dieciochesco. A diferencia de los pueblos que son portadores históricos de la razón universal, las naciones bárbaras (y sus pueblos) carecen de soberanía y de autonomía (Lander, 1993, p. 19).

La independencia de los estados americanos, plantea Quijano, no se concretó en la existencia de estados soberanos capaces de dar fin a la estructura de dominación ya que el proceso de construcción de las naciones latinoamericanos estuvo marcado por la colonialidad del poder (Quijano, 2000) a través del cual las poblaciones alterizadas continuaron sometidas a posiciones de subalternización y explotación (Rosenzvit, 2017). Y ya en el mundo contemporáneo, las diferencias sociales, culturales y políticas que produce la imposición mundial del neoliberalismo como matriz de política económica, tanto dentro de cada país como entre países, resulta en una erosión de forma continua de la autonomía (o soberanía) ${ }^{23}$, que se manifiesta fundamentalmente "en la des-democratización de la representación política de la sociedad en el estado y, de ese modo, en la des-nacionalización de la sociedad y del estado. Eso es lo que muestra, la asociación estructural entre las necesidades del capital financiero, de los mecanismos especulativos de acumulación, y las tendencias de reconcentración mundial del control de la autoridad pública" (2000, p. 9).

La pregunta es si existe un concepto de soberanía alternativa. La genealogía de la colonialidad da las primeras respuestas y busca sentar las bases de tal posibilidad. Tres hitos la jalonan: los tratados indígenas, la Conferencia de Bandung y los movimientos sociales contemporáneos.

La genealogía del pensamiento decolonial da comienzo con los tratados de Waman Poma de Ayala y Otabbah Cugoano. El primero, proponía un gobierno como un espacio de coexistencia entre diversas formas de pensamiento, con Castilla, por un lado, y entre varias comunidades dentro del Tawantinsuyu, por otro; es un "buen gobierno", una "co-existencia transnacional y co-existencia inter-cultural. Inter-cultural y no multi-cultural, porque en la propuesta de Waman Puma, Felipe no es el soberano de una estructura política hispánica en el Tawantinsuyu, sino que es el soberano del Felipe queda así des-colocado de su memoria, tradición, lengua, formación y pensamiento político" (Mignolo, 2008, p. 263). Por su lado,

${ }^{23}$ Quijano considera a la autonomía y la soberanía como equivalentes. 
Otabbah Cugoano proponía que la soberanía no debe establecerse en la relación de la persona con el estado, justamente por la afinidad o identificación del estado con una etnia en particular, sino la igualdad y libertad de persona a persona (Rincón, Millán, Rincón, 2015, p. 80).

Si bien en la Conferencia de Bandung, finalmente, primarían los intereses de los estados, vinculados a una prédica estatalista, soberanista y nacionalista, esta se encontraba asociada, a su vez, a la búsqueda de hegemonías regionales que participaba de alianzas/confrontaciones propias del orden bipolar regido por la Guerra Fría, como señala Joseph Hongoh:

For the Pan-African movement, Bandung represented an especially propitious forum, in which questions of emancipation and potential frameworks for substantive freedom could be explored in conversation with other colonised and newly independent peoples. (...) Here was a feeling of common history and identity, forged from shared anti-colonial struggle. Bandung embodied a geopolitical project through which the ideologies defining the Pan-African movement could be recast in a larger global context of equality and solidarity (2016, p. 380).

Desde esta última lectura, Bandung puede ser interpretada como el símbolo de la defensa de la soberanía estatal (en clave de liberación colonial) y la condena a la intervención de las grandes potencias en los estados. A su vez, "perseguía fundar las bases y visión común de un futuro que no fuera ni capitalista ni comunista, encontrando en ese sentido el camino "decolonial" (Rincón et. al. 2015, p. 81).

Por último, los movimientos sociales contemporáneos, tales como el Movimiento Sin Tierra de Brasil o los Foros Sociales, al seguir el camino de Bandung, han sostenido los derechos humanos frente a la globalización neoliberal y restituyen la soberanía como el poder y el control de los pueblos, y sujetos diversos sobre bienes que se consideran propios, en términos de poder del ser, del saber y del hacer. Como señala Enrique Dussel, en tanto liberación, la "única sede del poder es el pueblo" (2017), aunque cierto es que el pueblo en la lectura decolonial es una diversidad de actores sociales que deben ser reconocidos en sus espacialidades, temporalidades, subjetividades y demandas. Así, se presentan como narrativas liberacionistas la soberanía de las mujeres, de los cuerpos, de los pueblos originarios, pero también la soberanía del conocimiento, la salud, la ciencia, la tecnología, la cultura, los alimentos o el idioma, entre una multiplicidad de formas de revindicar el derecho a lo propio (Álvarez, 2016). 
La soberanía se presenta, entonces, como una liberación de la modernidad y de Occidente en general.

Desde la lectura decolonial, por tanto, la soberanía es dominación porque se presenta como un instrumento político y una categoría de análisis epistémica capaz de sustentar las bases de la colonialidad del poder y del ser. Sin embargo, también es liberación que se logra, fundamentalmente desde la soberanía nacional, lo cual expresa el protagonismo del poder de los sujetos. En palabras de Mignolo, la soberanía fue y sigue siendo un arma de doble filo. En cierta medida, como una respuesta o crítica a estas perspectivas y a las lecturas realizadas desde el Centro en general, la soberanía es un discurso de la modernidad que, al mismo tiempo, se ejerce como colonialidad del poder, es decir, como forma de control (Walsh, 2003, p. 18). Sin embargo, la soberanía nacional adquiere una valoración positiva como liberación desde donde se crean las condiciones para el surgimiento del sujeto local quien, desde y a través de los márgenes, comienza a contar sus propias historias (Lander, 2002; Walsh, 2003). La soberanía, entonces, es resistencia político-epistémica, ejercicio del poder y control sobre los recursos y bienes propios en una lectura en clave de soberanía interdependiente.

\section{Reflexiones finales}

A través del desarrollo de las Relaciones Internacionales -del Derecho Internacional a la constitución de la disciplina como una ciencia autónomala soberanía se presentó en América Latina como un concepto que fue objeto de referencia o análisis desde el campo doctrinario y teórico.

El recorrido de la disciplina y sus abordajes sobre la soberanía encontrarían, naturalmente, su correlato en la propia historia de América Latina, en sus relaciones con Europa, hasta comienzos del siglo XX y con Estados Unidos desde entonces, en un sistema internacional que viró de la centralidad del estado a los desafíos de la globalización en los tiempos contemporáneos.

Las Doctrinas buscarían responder a amenazas específicas y situaciones históricas determinadas, en las cuales las grandes potencias (Europa, hasta inicios del siglo XX y más tarde Estados Unidos) representarían amenazas y pruebas de fuerza el principio de la soberanía "acordado" en el ámbito universal por el Pacto westfaliano en 1648 y que los estados latinoamericanos debían garantizar a través de nuevas definiciones, 
caracterizaciones y/o aclaraciones sobre los alcances de su status jurídico tras la independencia de sus metrópolis. En el transcurrir del siglo XX, esa soberanía alcanzaría una significación política en términos de formas de relación con otros estados en el sistema internacional que pondrían de manifiesto las formas de vinculación que buscaban establecerse con las grandes potencias, en especial Estados Unidos, no solo la potencia hemisférica, sino también, claramente tras la Segunda Guerra Mundial, la potencia del mundo occidental-. El panamericanismo, el latinoamericanismo o iberoamericanismo marcarían las formas de alineamiento en el sistema internacional.

Las Teorías, por su parte, que adquirían un status latinoamericano desde el surgimiento del Estructuralismo hacia la segunda mitad del siglo XX, darían cuenta de la búsqueda de una soberanía política y económica que se configuró desde la comprensión del sistema internacional como centro y periferia en términos de dependencia de esta última y, ya hacia el fines del siglo XX, encontrarían en el concepto de soberanía una clave referencial para confirmar el rol del estado en la construcción de proyectos capaces de dirigir a las sociedades latinoamericanos a realizaciones basadas en sus propias realidades y sus proyectos de transformación económico- social, en tiempos en que la globalización, bajo un discurso de fin de la soberanía, imponía el liberalismo a escala global.

La globalización neoliberal también sería el escenario para otras lecturas teóricas latinoamericanas que, aún cuando adhirieran a esa configuración estructural, y convinieran en aceptar un nuevo orden mundial bajo las reglas de las grandes potencias, abordaron, desde el Realismo Periférico, la soberanía como un mito y un engaño que solo podía superarse aceptando los márgenes de maniobra reales de estados débiles, periféricos y poco estratégicos para los intereses de las grandes potencias. La autonomía como libertad era reemplazada así como autonomía en función de márgenes de maniobra.

Hacia la misma época, los estudios decoloniales comenzarían a revisitar la historia de Occidente y sus supuestos políticos, económicos, sociales y culturales que bajo el binomio modernidad/colonialidad habían construido una colonialidad del poder que nacía de la conquista y colonización de América y se perpetuaba hasta nuestros días. El concepto de soberanía sería entonces considerado como parte de la de la dominación-explotación de Occidente sobre el resto del mundo y América Latina en particular. La 
soberanía, sería en principio, un instrumento de dominación y perpetuación de la exterioridad y la diferencia, pero también una vía de liberación no ya solo de los estados, sino también de los sujetos y la soberanía se presentaría como el poder y el control de los sujetos y sociedades sobre los propios recursos. El Pacto westfaliano revertía el poder de los estados en el poder de los subalternos. De esta manera, ya no se trataría de una refundación de aquel Pacto, como pudo plantearlo el Estructuralismo, sino de una propuesta de carácter geocultural, de alcance global que plantearía la propia reescritura y elaboración de un Pacto alternativo al impuesto por Occidente en el cual el poder ya no residía solo en los estados y sus naciones sino en la diversidad de actores empoderados y resueltos a ejercer el control sobre espacios y recursos desde otros supuestos epistémicos.

A partir de lo expuesto, los abordajes realizados desde las Doctrinas y las Teorías contribuyen a problematizar y "descubrir", desde América Latina y en un plano continental, los límites del Pacto westfaliano, la inmutabilidad o permanencia de la soberanía estatal, la necesidad de precisiones conceptuales, la construcción de nuevos sentidos, la relativización o negación de su importancia o su reconfiguración en planos supraestatales que vuelven a los actores sociales como protagonistas. En todas estas posibilidades de análisis, media la realidad histórica y las elecciones en los modos de construir modelos de estado y de sociedad en relación con otros actores, en claves interestatales, estructurales o sistémicas.

\section{Bibliografía}

Aceves López, L. E. (2016). ¿Le hace falta un imperio al capital? Facultad de Economía Benemérita Universidad Autónoma de Puebla.

Aguirre Cortés, C. D. (2014). Los motivos de don Genaro: la formulación de la Doctrina Estrada en 1930. Tesis de Maestría inédita. Centro de Investigación y Docencia Económicas, Conacyt.

Akashi, K. (2010). Acta Pacis Westphalicae: Mythos et Veritas. Akashishoten (Japanese language).

Álvarez, S. T. (2012). Las soberanías del Mercosur. En R. Bernal Meza y S. T. Álvarez (Eds.) América Latina: integración e inserción (pp. 227264). Universidad de Santiago de Chile (IDEA - USACH). 
Álvarez, S. T. (2016). Integración y cultura. Estados, regiones y soberanías en revisión. En L. Weinberg (Coord.). Historia comparada de las Américas. Perspectivas de la integración cultural (pp. 81-114). CIALC.

Arenal, C. (1981). La génesis de las relaciones internacionales. Revista de Estudios Internacionales, 2 (4), 849-892.

Arrighi, G. (1998). La globalización, la soberanía estatal y la interminable acumulación del capital. Iniciativa Socialista, 48. Recuperado de: https://red.pucp.edu.pe/ridei/f

Atkins, G. P. (2019). Latin America in the International Political system. Routledge.

Barelli, C. B. (2008). La política exterior argentina durante las dos primeras presidencias de Juan Domingo Perón: aspectos Doctrinarios de la relación entre política interna y política exterior. Dunken.

Beaulac, S. (2000). The westphalian legal orthodoxy: Myth or Reality. Journal of history of international law, (2), 148-177.

Bello, F. (1970). La responsabilidad internacional del Estado. Doctrinas Calvo y Drago. Revista de Ciencias Jurídicas, (16), 7-19.

Berasategui, V. (2009). Carlos Saavedra Lamas. Buenos Aires. CARI.

Bernal Meza, R. (2018). Dos aportes teóricos latinoamericanos de relaciones internacionales y su utilización por el pensamiento chino contemporáneo: los casos de Prebisch y Escudé. Revista de estudios sociales, (64), 75-87.

Blin, A. y Marin, G. (Dirs.) (2013). Diccionario del Poder Mundial. Le monde diplomatique-FnGM-Editorial Aún creemos en los sueños. Recuperado de:

https://www2.worldgovernance.org/IMG/pdf_1036_Diccionario_del_Poder_Mundial.pdf

Bonilla, Y. (2014). Unsettling Sovereignty. Cultural anthropology, 32 (3), pp. 330-339.

Brum, B. (1920). Solidaridad americana. Máximo García Editor.

Calderón Salazar, J. (1996). Genaro Estrada. 1887-1937. Sesión solemne, LVI Legislatura. 
Cançado Trindade, A. C. y Martínez Moreno, A. (2003). Doctrina latinoamericana del Derecho Internacional, tomo I. Corte Interamericana de Derechos Humanos.

Carrillo Flores, A. (1965-1966). La Política Exterior de México. Foro Internacional, VI (2-3), 233-246.

Castro-Gómez, S. (2003). La Hybris del Punto Cero: Biopolíticas imperiales y colonialidad del poder en la Nueva Granada (1750-1810). Instituto Pensar, Universidad Javeriana.

Castro Peña, Y. (2007). El mito Roosevelt para América Latina. Universidad Simón Bolívar Ecuador/ Abya Yala/ Editorial Internacional.

Cerrano, C. (2019). El impacto de la Doctrina Rodriguez Larreta en la política interior uruguaya (1945-1946). Revista de la Facultad de Derecho, (47), 1-32.

Cervo, A. L. (2013). Conceptos en Relaciones Internacionales. Relaciones Internacionales, La Teoría de las Relaciones Internacionales en y desde el sur, (22), 149-166.

Chagas Bastos, F. H. (2018). La invención de la inserción internacional: fundaciones intelectuales y evolución histórica del concepto. Análisis político, (94), 10-30.

Clemente, A. (2020). De las Doctrinas Drago y Haya de la Torre a la "integración solidaria" de Puig: bases teóricas para la integración regional en el pensamiento latinoamericano. Revista Estudios Avanzados, (33), 28-39.

Clemente, I. (2012). Uruguay y el panamericanismo: ideas y alternativas en la política exterior de Uruguay. En R. Bernal Meza, R. y S. T. Álvarez (Eds.) Asuntos de América Latina (pp. 5-85), Universidad Santiago de Chile.

Conil Paz, A. (1975). Historia de la Doctrina Drago. Abeledo-Perrot.

Devés, E. y Álvarez, S. T. (2020). Problemáticas internacionales y mundiales desde el pensamiento latinoamericano. Ariadna.

Díaz Martínez, K. (2013) La Diplomacia de los Pueblos. Propuesta contrahegemónica en las Relaciones Internacionales. Revista Búsquedas políticas, 2 (1), 213-237. 
Dos Santos, T. (2003). Brasil: hacia un nuevo bloque histórico. Economía y Sociedad, (21), 29-46.

Dos Santos, T. (2020). Construir soberanía. Una interpretación económica de y para América Latina (edición al cuidado de Mónica Bruckman y Francisco López Segrera). CLACSO.

Drago, L. M. (1903). La República Argentina y el Caso de Venezuela: documentos, juicios y comentarios relacionados con la nota pasada al ministro argentino en Washington. Imprenta y Casa Editora de Coni Hermanos. Recuperado de: http://www.bibliotecadigital.gob.ar/items/show/847

Dussel, E. (2017). La única sede del ejercicio del poder es el pueblo. Palabra pública. Recuperado de: https://palabrapublica.uchile.cl/2017/10/17/enrique-dussel-la-unicasede-del-ejercicio-del-poder-es-el-pueblo/

Escudé, C. (1995). El Realismo de los Estados Débiles. La política exterior del primer gobierno de Menem frente a la teoría de las relaciones internacionales. Grupo Editor Latinoamericano.

Escudé, C. (1998). Foreign Policy Theory in Menem 's Argentina, Gainsville, University Press.

Escudé. C. (2011). ¿Realismo filosófico y fin de la historieta? Serie Documentos de Trabajo 476, UCEMA.

Escudé, C. (2012). Principios de realismo periférico: vigencia de una teoría argentina ante el ascenso de China. Lumière.

Escudé, C. (2019). La carta china: neutralizando la gripe del fin del mundo. Revista Argentina de Ciencia Política, 1 (25), 161-177.

Fernández Palacios, J. M. (2011). Antecedentes de la Doctrina Monroe: Posibilidades reales y percepciones acerca de una intervención de la santa alianza en Hispanoamérica. Ab initio (3), 73-96.

Ferrer, A. (2007). Globalización, desarrollo y densidad nacional. En G. Vidal y R. A. Guillén (Comps.) Repensar la Teoría del desarrollo en un contexto de globalización. Homenaje a Celso Furtado (pp. 431-437), CLACSO.

Ferrer, A. (2012). La suspensión del fallo de Griesa es razonable. Diario La jornada, 29 de noviembre. 
Ferrer, A.; Prebisch, R.; Furtado, C. (1984). Deuda y soberanía. El Cid editor.

Galindo Rodríguez, F. (2013). Enfoques postcoloniales en Relaciones Internacionales: un breve recorrido por sus debates y sus desarrollos teóricos. La Teoría de Relaciones Internacionales en y desde el Sur. Relaciones Internacionales, (22), 85-107.

Gaytán, R. I. (2018). La Doctrina Carranza. Práctica internacional y legado Doctrinario. INEHRM.

Geertz, C. (2004). What Is a State If It Is Not a Sovereign? Reflections on Politics in Complicated Places. Current Anthropology, 45 (5), 577-593.

Gómez Vélez, M. I.; Saldarriaga Grisales, D. C; López Gil, M. C; Zapata Botero, L. M. (2017). Estudios decoloniales y poscoloniales. Posturas acerca de la Modernidad/ Colonialidad y el Eurocentrismo. Revista Ratio Juris, 12 (24), 27-60.

Grosfoguel, R. (2006). La descolonización de la economía política y los estudios postcoloniales: transmodernidad, pensamiento fronterizo y colonialidad global. Tábula Rasa (4), 17-48.

Hardt, M y Negri, A. (2002). Imperio. Paidós.

Heredia, E. A. (2008). América como antecedente de la historiografía de las relaciones internacionales latinoamericanas: historiografías y Teorías. Estudos Ibero-Americanos, XXXIV (1), 7-35.

Hongoh, J. (2016). The Asian-African Conference (Bandung) and PanAfricanism: the challenge of reconciling continental solidarity with national sovereignty. Australian Journal of International Affairs, 70 (4), 374-390. https://doi.org/10.1080/10357718.2016.1168773

Jaguaribe, H. (1979). Autonomía periférica y hegemonía céntrica. Estudios Internacionales, 12 (46), 91-96.

Jaguaribe, H. (2001). América Latina y los procesos de integración. AmerSur, diciembre. Recuperado de: http://www.amersur.org/Integ/Jaguaribe.htm

Juárez, Benito (1998). Manifiesto de don Benito Juárez a los mexicanos (15 de julio de 1867). En R. Iglesias (Comp.) (1998). Planes políticos, proclamas, manifiestos y otros documentos de la Independencia al 
México moderno, 1812-1940. UNAM, Instituto de Investigaciones jurídicas.

Krasner, S. (2001). Soberanía: hipocresía organizada. Paidós.

Kunz, D. (2012). Ontología y relaciones internacionales. Repensando el espacio político internacional desde el post-estructuralismo. Letras Internacionales, (153-6).

Recuperado

de: https://revistas.ort.edu.uy/letras-internacionales/issue/view/58

Lander, E. (1993). Ciencias sociales: saberes coloniales y eurocéntrico. En E. Lander (Comp.). La colonialidad del saber: eurocentrismo y ciencias sociales. Perspectivas latinoamericanas (pp. 4-23). CLACSO.

Lander, E. (2002). La utopía del mercado total y el poder imperial. Revista Venezolana de Economía y Ciencias Sociales, 8 (2), 51-79.

Marini, R. M. (1985). La lucha por la democracia en América Latina. Cuadernos del Pensamiento Crítico Latinoamericano, 1. Buenos Aires, CLACSO.

Recuperado

de: http://biblioteca.clacso.edu.ar/ar/libros/secret/cuadernos/marini/marini. pdf

Menezes, W. (2010). Derecho Internacional en América Latina. Fundação Alexandre de Gusmão.

Meyer, L. (2008). México y la soberanía relativa. El vaivén de los alcances y los límites. Foro internacional, XLVIII (4), 765-784.

Mignolo, W. (2008). La opción de-colonial: desprendimiento y apertura. Un manifiesto y un caso. Tábula Rasa, (8), 243-281.

Mignolo, W. (2015). La colonialidad: la cara oculta de la Modernidad. En W. Mignolo. Habitar la frontera: sentir y pensar la descolonialidad (Antología, 1999-2014) (pp. 25-48), CIDOB, UACJ.

Monroe, J. (1823). The Monroe Doctrine from the President's Annual Messege to Congress. Gilder Lehrman Collection. Recuperado de: https://www.gilderlehrman.org/history-resources/spotlight-primarysource/monroe-doctrine-182300

Moya Domínguez, M. T. (2004). Manual de Derecho Internacional público. Ediar.

Ojeda, M. (1986) [1927]. Alcances y límites de la política exterior de México (2da. ed.) El Colegio de México. 
Ortiz Ahlf, L. (2018). Derecho Internacional Público [cuarta edición]. Oxford University Press.

Osiander, A. (2001). Sovereignty, International Relations, and the Westphalian Myth. International Organization, 55 (2), 251-287.

Perón, J. D. (1947). Perón expone su Doctrina. Teoría y Doctrina del peronismo. Editorial Nueva Argentina.

Perón, J. D. (1948). La Política Internacional Argentina. S/E.

Pourmokhtari, N (2013). Sovereignty in IR: the contradictory legacy of a 'West Centric' discipline. Third World Quarterly, 14 (10), 1767-1793.

Quijano, A. (2000). Colonialidad del poder, globalización y democracia, S/E.

Ramallo, F. (2014). Enseñanzas de la historia y lecturas descoloniales: entrecruzamientos hacia los saberes de otros mundos posibles. Revista Entramados-Educación y Sociedad (1), 43-59. https://fh.mdp.edu.ar/revistas/index.php/entramados/article/view/1077

Rapoport, M. y Spiegel, C. (2009). Estados Unidos y el peronismo. Planeta.

Rincón, Or.; Millán, K. y Rincón Om. (2015). El asunto decolonial: Conceptos y debates. Perspectivas. Revista de Historia, Geografía, Arte y Cultura, 3 (5), 75-95.

Rosenzvit, D. (2017). La dialéctica de Calibán: pensamientos descolonizantes para la cuestión negra en América Latina. Iconos Revista de Ciencias Sociales (57), 61-77 https://revistas.flacsoandes.edu.ec/iconos/article/view/2262/1541

Russell, R. y Tokatlian, G. (2013). América Latina y su gran estrategia: entre la aquiescencia y la autonomía. Revista CIDOB d'Afers Internacionals (104), 157-180.

Rutherford, D. (2012). Laughing at Leviathan. sovereignty and audience in West Papua. Chicago Studies in Practices of Meaning.

Schenoni, L. and Escudé, C. A. (2016). Peripheral Realism Revisited. Revista Brasileira de Política Internacional, 59 (1), 1-18.

Serbín, A. (2010). Regionalismo y soberanía nacional en América Latina. Los nuevos desafíos, Documentos CRIES, 15.

Shibasaki, A. (2014). Myths in a Discipline: IR and "the Peace of Westphalia". Journal of Global Media Studies, 14, 41-52. 
Sunkel, O. (1967). Política nacional de desarrollo y dependencia externa. En Serie: Documentos Teóricos, 4, Instituto de Estudios Peruanos.

Suñé, N. (2015). Arbitraje en América Latina. Consideraciones en materia de inversiones. Revista de la Secretaría del Tribunal Permanente de Revisión, 5, 191-216.

Tah Ayala, E. D. (2021). El principio de no intervención en América Latina: el corolario Roosevelt y la Doctrina Drago. Intersticios Sociales (21), 173-196.

Teschke, B. (2003). The Myth of 1648: Class, Geopolitics, and the Making of Modern International Relations. Verso.

Tickner, A. B. (2012). Relaciones de conocimiento centro-periferia: hegemonía, contribuciones locales e hibridización. Politai, 3 (4), 163172. http://revistas.pucp.edu.pe/index.php/politai/article/view/14105

Torres, B. (2010). Los años de Díaz Ordaz: El interés en los vecinos. En México y el Mundo. Historia de sus Relaciones Exteriores [Tomo VII: De la Guerra al Mundo Bipolar] (pp.169-196), El Colegio de México.

Tomassini, L. (1988). Relaciones Internacionales: Teoría y práctica, Documento de trabajo 2, PNUD-CEPAL.

Tovar Ruiz, J. (2011). Cuatro momentos de la Doctrina en política exterior estadounidense: ¿Entre la Teoría y la práctica? Revista CIDOB d'afers internacionals, (95), 165-187.

Trask, R. (2015). The impact of the Cold War on US-Latin American Relations, 1945. En M.J. La Rosa y F. O. Mora. (Eds.) Neighborly Adversaries. Readings on US-Latin American Relations (pp. 129-14), Rowan and Littlefield.

UNESCO (s.f). Concept of governance. International Bureau of Education. Recuperado de: http://www.ibe.unesco.org/en/geqaf/technicalnotes/concept-governance

Valverde Barrera, A. (1961). Cursillo de Derecho Internacional Público. Cuaderno 25. Publicaciones de La Facultad de Derecho.

Wachspress, M. (2009). Rethinking sovereignty with reference to history and anthropology. Cambridge University Press. 
Wallerstein, I. (2017). El mito de la soberanía. La jornada, octubre. Recuperado de: https://www.jornada.com.mx/2017/10/08/opinion/023a1mun

Walsh, C. (2003). Las geopolíticas del conocimiento y colonialidad del poder. Entrevista a Walter Mignolo. En C. Walsh, F. Schiwy y S. Castro-Gómez (Eds.) Indisciplinar las ciencias sociales. Geopolíticas del conocimiento y colonialidad del poder. Perspectivas desde lo Andino (pp. 1-27), UASB/Abya Yala.

Zuccarino, M. (2018). De la Comisión de Neutrales de Washington a la Conferencia de Paz en Buenos Aires. El rol desempeñado por la Argentina en las negociaciones de paz del Chaco. Res Gesta (54), 103-126.

Recuperado

de:

https://erevistas.uca.edu.ar./index.php/RGES/article/view/1432

Zuccarino, M. (2019). Europeísmo versus panamericanismo: Su incidencia en la posición del Gobierno argentino ante la Guerra del Chaco. Revista de Historia Americana y Argentina, 54 (1), 83-127. 